\title{
Review Article \\ Dengue in the United States of America: A Worsening Scenario?
}

\author{
Germán Añez and Maria Rios \\ Laboratory of Emerging Pathogens, DETTD/OBRR/CBER, U.S. Food and Drug Administration, Bethesda, MD 20892, USA
}

Correspondence should be addressed to Germán Añez; german.anez@fda.hhs.gov and Maria Rios; maria.rios@fda.hhs.gov

Received 23 May 2013; Accepted 3 June 2013

Academic Editor: Ernest A. Gould

Copyright (C) 2013 G. Añez and M. Rios. This is an open access article distributed under the Creative Commons Attribution License, which permits unrestricted use, distribution, and reproduction in any medium, provided the original work is properly cited.

\begin{abstract}
Dengue is a febrile illness caused by any of the four dengue virus types (DENV-1 to -4, genus Flavivirus, family Flaviviridae) mainly transmitted by the mosquito Aedes aegypti. DENV can be transmitted by blood transfusion. Dengue has been historically present in the continental United States (US), in the state of Hawaii, and in the US insular territories in the Caribbean and the Pacific. During the second half of the 20th century, most of the cases reported in the US were imported cases brought to the country by travelers. Since 2009, cases of autochthonous dengue have been recognized in the state of Florida after 75 years of absence, followed by intensification of transmission in endemic places including the US territories of US Virgin Islands and Puerto Rico, which experienced a large dengue epidemic in 2010. The widespread distribution of dengue mosquito vectors, deficient mosquito control measures and increased frequency of DENV-infected visitors to the US coming from dengue-endemic locations or places experiencing epidemics appear to be jointly responsible for the emergence and reemergence of dengue in the US and its territories.
\end{abstract}

\section{Introduction}

Dengue, the most prevalent arthropod-borne viral disease in the world, is an acute, febrile disease caused by any of the four dengue virus types (DENV-1 to -4, genus Flavivirus, family Flaviviridae) [1]. DENV is naturally transmitted by mosquitoes from the genus Aedes, mainly by the urban species Aedes aegypti, and in some geographical regions by Aedes albopictus. Infection by dengue viruses can be asymptomatic or cause disease of variable degree of severity. Dengue ranges from a mild, influenza-like illness known as dengue fever (DF) to a severe and potentially life-threatening condition called dengue hemorrhagic fever (DHF). DHF can ultimately evolve to hypovolemic shock (dengue shock syndrome (DSS)) and death [2]. DHF and DSS are classified as severe dengue in the newest World Health Organization (WHO) dengue clinical classification [3].

DENV can also be transmitted by transfusion of blood and blood components and by solid organ transplants containing infectious virus [4-6]. Dengue is endemic in most countries of tropical America, the Caribbean and Southeast Asia, and causes episodic epidemics in islands of the Pacific and in Africa [7, 8]. Many DENV endemic regions are hyperendemic, which is defined by the circulation of all DENV types in a specific geographical area. This may increase the opportunity for occurrence of secondary infections with increased clinical severity via antibody-dependent enhancement of the infection by sub-neutralizing concentrations of anti-dengue antibodies in individuals previously infected with a different dengue type (heterologous infection) [9].

Approximately, 50-100 million cases of dengue were calculated to occur each year around the globe [3]. However, the newest estimates raise these numbers to about 390 million cases per year (range 284-528), from which approximately 96 (range 67-136) will present clinical manifestations of any severity [10]. Despite its low lethality rates, dengue causes severe economic and social disruption and has profound impact on the welfare of regions affected by the disease since it is endemic mostly in developing countries where healthcare systems have limited resources [11-13]. After many years of continuous efforts, there are still neither effective vaccines nor specific antiviral treatments available against DENV [14].

The mosquitoes that serve as DENV vectors have been able to reach sub-tropical and temperate regions, including North America and countries in Europe [15-17]. In addition, DENV brought in by infected travelers has been able to establish autochthonous infection cycles in some of these countries. DENV is considered the most common cause of 
febrile illness in travelers returning to the USA from destinations in the Americas and Asia [18].

The scope of this review is to provide an analysis of the epidemiology of dengue in the United States and its territories, with emphasis on the changes in dengue activity in the last decade and on aspects on the molecular epidemiology of currently circulating DENV.

\section{Dengue in the United States}

Dengue is thought to have been present in the USA since the end of the 18th century, when Dr. Benjamin Rush, a physician and signatory of the US Declaration of Independence, described a disease resembling dengue fever in Philadelphia during 1780 [27]. During the first half of the 20th century, a number of dengue outbreaks were reported in the continental USA, especially in the gulf and southeastern states (i.e., Alabama, Florida, Georgia, Louisiana, Mississippi and Texas), in the state of Hawaii, and in the USA Territories in the Caribbean and the Pacific Ocean (Table 1).

The continental USA comprises the 48 contiguous states and the District of Columbia, and the non-contiguous states of Alaska in North America and Hawaii in the Pacific Ocean and a number of unincorporated territories including Puerto Rico and the US Virgin Islands (USVI) in the Caribbean and American Samoa, Guam, and the Northern Mariana Islands in the Pacific Ocean [19].

Autochthonous dengue has been reported sporadically in the Mexico-Texas border, where indigenous cases of dengue reappeared in 1980 after more than 30 years of absence. Since then, most dengue cases reported in the USA have been imported, brought by infected travelers returning from visits to endemic countries or places experiencing dengue epidemics. Dengue has also been present in the state of Hawaii, the US territories in the Pacific (American Samoa, Guam, and Northern Mariana Islands) and the territories of Puerto Rico and USVI. In 2009, after over 70 years of absence, autochthonous dengue reappeared in the state of Florida (Figure 1).

In all those instances, dengue outbreaks were facilitated by the presence of the mosquito vector, the favorable climatic conditions for its subsistence, and the presence of susceptible individuals. The dengue mosquito vectors Aedes aegypti and Aedes albopictus have been reported to be present in several counties in the USA, especially in the Southern and Southeastern regions of the country [28] (Figure 2).

2.1. Dengue in the Mexico-Texas Border. The first autochthonous case of dengue reported in the USA since 1945 occurred in Brownsville, Texas in 1980 when DENV-1 was isolated from a 5-year-old girl that did not have history of travel outside Brownsville (Table 1). Brownsville is located across the Rio Grande from the city of Matamoros in the state of Tamaulipas, Mexico where many years of dengue activity had been observed [21].

Subsequently, surveillance studies reported 63 additional dengue cases (all caused by DENV-1) that were laboratory confirmed in Texas, 52 of which occurred in counties contiguous to the Mexico-Texas border [30]. Six years later, autochthonous transmission of DENV-1 was again reported in at least 9 individuals in Texas [22]. The Mexico-Texas border region is at risk for dengue endemicity due to the presence of the competent mosquito vectors Aedes aegypti and Aedes albopictus and to the circulation of all DENV types (DENV-1 to -4$)$ in recent years [31]. In sum, dengue has been detected in residents of seven Texas counties: Bee, Cameron (where Brownsville is located), Hidalgo, Maverick, Nueces, Travis, and Webb [23, 30, 32].

In 2005, a woman who had not traveled to Mexico in the months before the onset of dengue symptoms developed DHF, and this was the first case of autochthonous DHF reported in Texas. During that year, a large dengue epidemic developed in the neighboring Mexican state of Tamaulipas with more than 1,200 dengue cases of which 223 (18\%) were classified as DHF. Meanwhile, 25 dengue cases were reported in Brownsville, of which at least three were locally acquired [32]. The disparities in the number of cases observed on different sides of the border have been explained by the higher standard of living in the USA including the use of air-conditioners and the presence of nets in doors and windows, which remain closed most of the time reducing the density of indoor mosquitoes thus minimizing the risk of mosquito bites [33].

2.2. Dengue in Florida. After 75 years without reports of dengue activity in Florida, a case was identified in 2009 in a New York patient who had traveled to Key West (Table 1). This individual had not traveled to any other place either in the USA or abroad before the onset of symptoms, and the case was laboratory-confirmed by the Centers for Disease Control and Prevention (CDC) using RT-PCR. A serosurvey conducted in 2009 revealed that at least $5.4 \%$ of the residents of Key West had serological evidence of recent dengue infection [24].

According to the Florida State Department of Health, between 2009 and 2012, a total of 103 autochthonous dengue cases have been reported in Florida including those from the outbreak of 2009. Of these, 27 were reported in 2009 in Key West (Monroe county), 65 during 2010 (Broward, Miami-Dade, and Monroe counties), 7 in 2011 (Hillsborough, Martin, Miami-Dade, and Palm Beach counties) and 4 in 2012 (Miami-Dade, Seminole, and Osceola counties) [25, 26], (Table 2).

DENV-1 was detected in mosquito pools collected in Key West [49] and in a blood donor from Key West during 2010 [50]. The strains isolated from these two specimens were sequenced, and subsequently, a number of DENV-1 strains obtained from samples from dengue cases from Key West/ Monroe county (8 patients) and one strain each from patients from Broward, Miami-Dade, Orange, and Pinellas counties were sequenced [51]. All DENV-1 strains from Florida from 2009-2010 sequenced to date (obtained from mosquito pools, dengue cases, and a blood donor) belong to the genotype $\mathrm{V}$ of the virus and have phylogenetic relationships with Central American strains; however, all but one of the strains sequenced from Key West grouped together in the phylogenetic trees, suggesting that in situ microevolution has occurred and that this Key West sublineage was transmitted 
TABLE 1: Dengue activity in the continental USA between 1780 and 2013.

\begin{tabular}{|c|c|c|}
\hline Year(s) & Activity reported & References \\
\hline 1780 & Dengue suspected in Philadelphia, PA & {$[19]$} \\
\hline 1826 & USA ports report 1st dengue outbreak & {$[20]$} \\
\hline $1827-1828$ & Epidemic in Southern USA & {$[20]$} \\
\hline 1845 & Dengue reported in St. Louis, MO & {$[20]$} \\
\hline $1850-1851$ & $\begin{array}{l}\text { 1st report of dengue epidemic inland (including GA and MS), epidemic in Southern USA, New Orleans, LA, } \\
\text { and along South Coast }\end{array}$ & [20] \\
\hline $1870-1872$ & Epidemic in Southern USA & {$[20]$} \\
\hline 1873 & Dengue reported in $\mathrm{LA}, \mathrm{AL}$, and $\mathrm{MS} ; \approx 40,000$ cases reported in New Orleans & {$[20]$} \\
\hline $1879-1880$ & Epidemic in Southern USA & {$[20]$} \\
\hline $1885-1886$ & Dengue in gulf ports of TX, dengue in Austin, 16,000 estimated cases of 22,000 inhabitants & {$[20]$} \\
\hline $1897-1903$ & Epidemic in Southern USA, TX most heavily affected & {$[20]$} \\
\hline 1904 & Dengue reported in FL and TX & {$[20]$} \\
\hline 1916 & Fatal case of possible DHF reported in TX & {$[20]$} \\
\hline 1922 & Dengue epidemic, 500,000 to 600,000 cases in TX, 30,000 in Galveston, and 7,561 in LA & {$[20]$} \\
\hline 1923 & 1,376 dengue infections reported in LA & {$[20]$} \\
\hline 1924 & 1 dengue case in LA & {$[20]$} \\
\hline $1941-1944$ & Texas and gulf states involved in epidemic & {$[20]$} \\
\hline 1945 & Last continental epidemic of dengue reported in LA & {$[20]$} \\
\hline 1980 & 1st indigenous dengue cases in USA since 1945 (Brownsville, TX), DENV-1 isolated & {$[21]$} \\
\hline 1981 & DENV- 4 cases reported, 1 st isolation of DENV-4 in the USA & {$[20]$} \\
\hline 1982 & 1st reports of DENV-2 in the USA & {$[20]$} \\
\hline 1983 & 1st reports of DENV-3 in the USA & {$[20]$} \\
\hline 1986 & DENV-1 reported in TX & {$[22]$} \\
\hline 1987 & Autochthonous dengue reported in TX & {$[20]$} \\
\hline 1990 & DENV-1, -2 , and -3 isolated in the USA, reports of 102 dengue cases & {$[20]$} \\
\hline 1991 & DENV-1 and DENV-3 isolated in the USA, 25 dengue cases reported & {$[20]$} \\
\hline 1994 & 91 cases of dengue, DENV-2 and -3 isolated in the USA & {$[20]$} \\
\hline 2005 & First case of autochthonous DHF case reported in TX & {$[23]$} \\
\hline $2009-2011$ & $\begin{array}{l}\text { Autochthonous dengue transmission in FL, DENV-1 isolated. DENV-1 isolated from a blood donor from Key } \\
\text { West, FL in } 2010\end{array}$ & [24-26] \\
\hline 2012 & 4 DENV cases reported in FL, 2 of them in Miami-Dade & {$[26]$} \\
\hline $2013^{*}$ & No indigenous dengue cases reported & {$[25]$} \\
\hline
\end{tabular}

Adapted from [20].

AL: Alabama, FL: Florida, GA: Georgia, LA: Louisiana, MO: Missouri, MS: Mississippi, PA: Pennsylvania, and TX: Texas.

*As of May 10, 2013.

during 2009 and 2010 (Figure 3) [50, 51]. Sequences of DENV-1 strains obtained from cases acquired in other counties in Florida clustered in a separate phylogenetic group, more closely related to Central American strains (i.e., from Costa Rica, Mexico, and Nicaragua). Only one DENV-1 strain from Key West was found clustering outside the Key West lineage, which suggests that introduction of at least two different DENV-1 lineages occurred in Key West during 2009-2010 epidemics [51] (Figure 3).

The dengue outbreak of 2009-2010 has been linked to Aedes aegypti, which is prevalent in Monroe county where Key West is located. Although Aedes albopictus is present in Florida, it has not become established in Monroe county.
Mosquitoes from both Aedes species obtained from colonies in the state of Florida were experimentally infected with a DENV-1 strain isolated from Key West, and vector competence for this virus was assessed. There were no significant differences in the rates of infection, dissemination, and transmission between these two mosquito species occurring in Florida. The entire genome of the DENV-1 specimen utilized in this vector competence study has been sequenced [16] and shown to cluster within the Key West lineage (Figure 3).

In addition to the autochthonous cases, an important number of dengue imported cases (392) from travelers to countries in Central and South America, the Caribbean, Africa, the Middle East, and South and Southeast Asia have 
TABLE 2: Imported and autochthonous cases of dengue reported in the state of Florida, USA, 2009-2013 (as of April 27, 2013).

\begin{tabular}{|c|c|c|c|c|}
\hline Year & $\begin{array}{c}\text { Number of } \\
\text { imported cases }\end{array}$ & Countries visited ${ }^{*}$ (number of cases) & $\begin{array}{l}\text { Number of } \\
\text { autochthonous cases }\end{array}$ & $\begin{array}{l}\text { Florida counties } \\
\text { (number of cases) }\end{array}$ \\
\hline 2009 & 36 & $\begin{array}{l}\text { BO (2), BR, CO (2), DO (3), GT (2), HT (10), HN } \\
\text { (2), IN (3), MY, MX, NI, PA (3), PH, PR (3), SR }\end{array}$ & 27 & Monroe (27) \\
\hline 2010 & 133 & $\begin{array}{l}\text { BD, BR, KY, CO (8), CR (4), CU, DO (13), EC, SV, } \\
\text { GH, GD (4), GT (2), HT (6), HN (6), JM (5), MQ } \\
\text { (2), MV, MX, NI (13), PK, PH, PR (36), TH, TT, VE } \\
\text { (16), VI (3), MY/AE/BD }{ }^{* *}, \mathrm{PA} / \mathrm{VE}^{* *}\end{array}$ & 65 & $\begin{array}{l}\text { Broward (1), Miami-Dade (1), } \\
\text { and Monroe (63) }\end{array}$ \\
\hline 2011 & 61 & $\begin{array}{l}\text { AW, BS (14), BD (3), BR (3), CO, CR, CU (5), DO, } \\
\text { GD, GY, HT (2), IN, JM (2), NI (2), PK, PA (2), PR } \\
\text { (11), LC (2), TT (4), TC, VE, VN }\end{array}$ & 7 & $\begin{array}{l}\text { Hillsborough (1), Martin (1), } \\
\text { Miami-Dade (3), and Palm } \\
\text { Beach (2) }\end{array}$ \\
\hline 2012 & 135 & $\begin{array}{l}\text { BR, CO, CU (29), DO (17), EC (4), } \\
\text { SV (2), GH, GY (2), HT (17), HN, IN, JM (23), MX } \\
\text { (2), NI (2), PA, PH (4), PT, PR (16), ZA, LK, VC, SR, } \\
\text { TT (4), TC, VI }\end{array}$ & 4 & $\begin{array}{l}\text { Miami-Dade (2), Seminole (1), } \\
\text { and Osceola (1) }\end{array}$ \\
\hline 2013 & 27 & $\begin{array}{l}\text { AO, BB, BR, CO (2), DO (3), GT, HT, ID, JM (3), } \\
\text { NG, PH, PR (8), MF }\end{array}$ & 0 & - \\
\hline Total & 392 & & 103 & \\
\hline
\end{tabular}

*AE: United Arab Emirates, AO: Angola, AW: Aruba, BB: Barbados, BD: Bangladesh, BO: Bolivia, BR: Brazil, BS: Bahamas, CO: Colombia, CR: Costa Rica, CU: Cuba, DO: Dominican Republic, EC: Ecuador, GD: Grenada, GH: Ghana, GT: Guatemala, GY: Guyana, HT: Haiti, HN: Honduras, ID: Indonesia, IN: India, JM: Jamaica, KY: Cayman Islands, LC: Saint Lucia, LK: Sri Lanka, MF: Saint Martin, MQ: Martinique, MY: Malaysia, MX: Mexico, MV: Maldives, NG: Nigeria, NI: Nicaragua, PA: Panama, PH: The Philippines, PK: Pakistan, PR: Puerto Rico, PT: Portugal, SR: Suriname, SV: El Salvador, TC: Turks and Caicos Islands, TH: Thailand, TT: Trinidad and Tobago, VC: St. Vincent and the Grenadines, VE: Venezuela, VI: US Virgin Islands, VN: Vietnam, and ZA: South Africa. ${ }^{* *}$ Travel to more than one country.

Source: Florida State Department of Health $[25,26]$.

TABle 3: Dengue activity in the state of Hawaii and the Territories of American Samoa, Guam, and Northern Mariana Islands, 1840 s-2010.

\begin{tabular}{|c|c|c|}
\hline Year(s) & Activity reported & References \\
\hline Late 1840 s & First large dengue epidemic recorded in HI, associated with Aedes aegypti & {$[34]$} \\
\hline 1903 & Large dengue epidemic in $\mathrm{HI}, \approx 30,000$ cases, associated with Aedes aegypti & {$[35]$} \\
\hline 1943-1944 & DENV-1 epidemic in $\mathrm{HI}, \approx 1,500$ cases & {$[34,36]$} \\
\hline 1944 & Aedes aegypti reported to be eradicated from GU. Aedes albopictus reported to be present in the island & [37] \\
\hline$<1950$ & Dengue cases were reported in AS and GU before 1950, no dengue epidemics reported in GU in recent times & {$[38]$} \\
\hline 1995 & Possible dengue infection in German visitors to $\mathrm{HI}$ & {$[39]$} \\
\hline 1972 & Dengue epidemic in AS (DENV-2) & {$[40]$} \\
\hline 1975 & Dengue epidemic in AS (DENV-1) & {$[38,40]$} \\
\hline 1995-1996 & Dengue epidemic in AS (DENV-3) & {$[38]$} \\
\hline 1997 & Reports of dengue cases in AS & {$[41]$} \\
\hline 1998 & $\begin{array}{l}\text { Dengue seropositive individuals reported in Saipan (MP) during 1998, DENV-2 implicated in epidemic } \\
\text { activity }\end{array}$ & {$[42,43]$} \\
\hline \multirow{2}{*}{2001} & More than 1,600 dengue cases reported in AS (DENV-1), 3 deaths & {$[44]$} \\
\hline & Dengue outbreak in the MP, $>1,400$ cases reported & {$[45]$} \\
\hline 2001-2002 & $\begin{array}{l}\text { Autochthonous transmission of dengue in HI, } 122 \text { confirmed cases, DENV-1 isolated, and Aedes albopictus } \\
\text { was the implicated vector }\end{array}$ & {$[46]$} \\
\hline 2007 & 63 dengue cases confirmed in AS, 23 cases hospitalized & {$[47]$} \\
\hline 2008 & Dengue activity reported in AS & {$[48]$} \\
\hline 2009 & Outbreak of $\approx 400$ confirmed cases in AS & {$[48]$} \\
\hline 2010 & $\begin{array}{l}\text { Dengue cases reported in AS. Serosurvey conducted in } 2010 \text { revealed }>95 \% \text { of the tested individuals as } \\
\text { seropositive for dengue }\end{array}$ & {$[8,48]$} \\
\hline
\end{tabular}

AS: American Samoa, GU: Guam, HI: Hawaii, and MP: Northern Mariana Islands. 


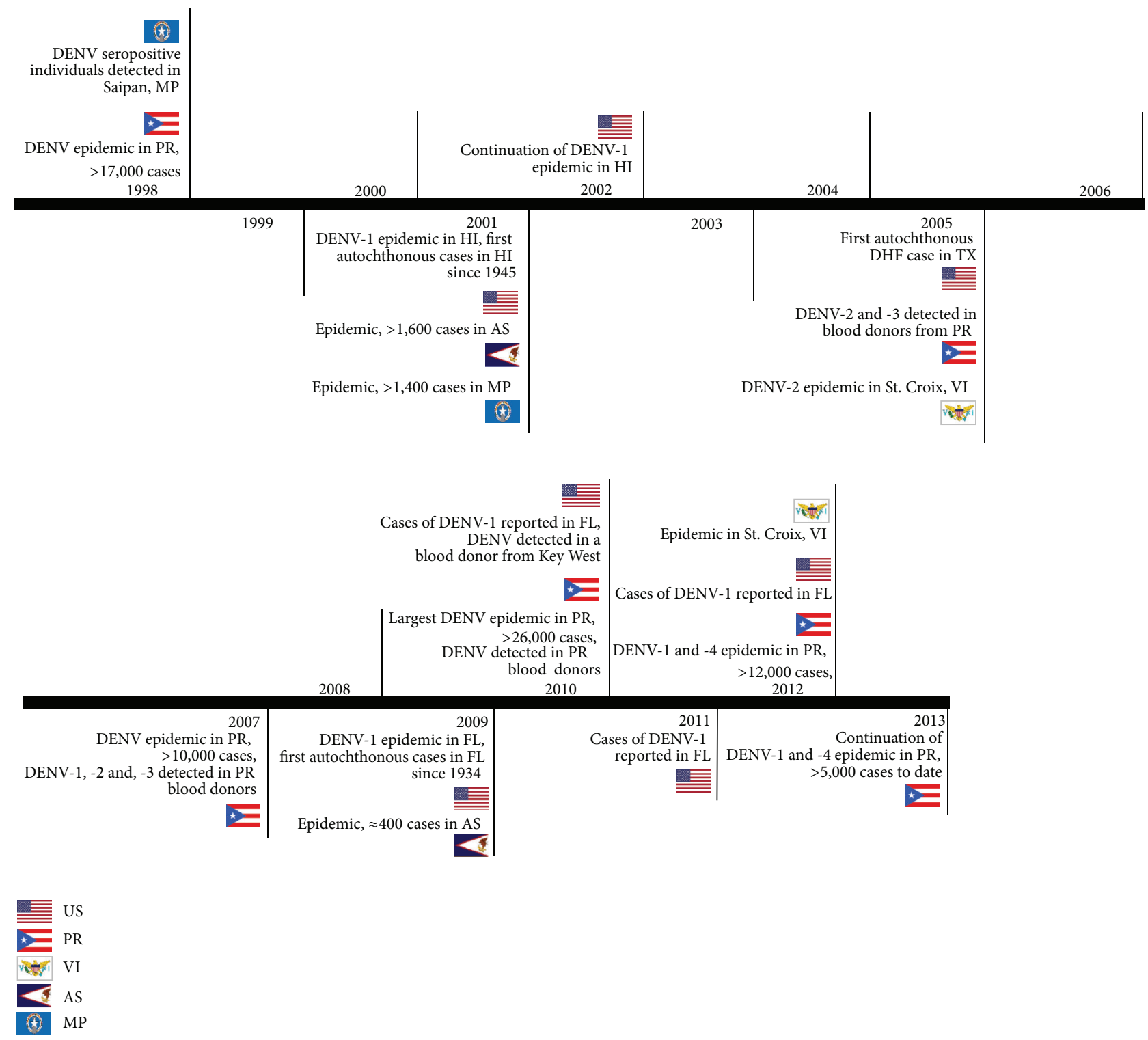

Figure 1: Timeline of selected recent dengue activity in the U.S. and its territories, 1998-2013. U.S.: United States; representing the states of Florida (FL), Hawaii (HI) and Texas (TX), P.R.: Puerto Rico, V.I.: U.S. Virgin Islands, A.S.: American Samoa, M.P.: Northern Mariana Islands. Numbers shown represent dengue reported cases.

been reported in Florida since 2009 [25, 26] (Table 2). The wide geographical area of origin of dengue imported cases in Florida reflects the importance of the Miami International Airport as a gateway to the USA and a possible route of entry for these and other pathogens.

2.3. Dengue in Hawaii. The first large dengue epidemic on record occurred in Hawaii in the mid-19th century. Another large epidemic occurred in 1903 with approximately 30,000 cases reported $[34,35]$. Aedes aegypti was the vector implicated in those dengue outbreaks. But at a certain point during the early 20th century, Aedes albopictus was introduced in these islands and displaced Aedes aegypti [52].

A DENV-1 epidemic occurred in Hawaii from 1943 to 1944 , with almost 1,500 cases reported $[36,53]$. As in the continental USA no autochthonous cases of dengue were reported after 1945 and imported dengue cases were reported at a low frequency in Hawaii [54]. In 1995, two German travelers developed symptoms compatible with dengue infection after a trip to Hawaii [46] (Table 3).

However, in 2001, following 56 years without reports of autochthonous dengue cases, an epidemic occurred in the island of Maui. A total of 122 laboratory-confirmed dengue cases were reported between 2001 and 2002, 92 of which occurred in Maui, 26 in Oahu, and 4 in Kauai. DENV-1 was the type identified in viral isolates obtained from 15 cases from Hawaii, and the mosquito vector implicated in this epidemic was Aedes albopictus [54].

Molecular epidemiologic studies suggest that at least two distinct DENV-1 strains were introduced in Hawaii during 


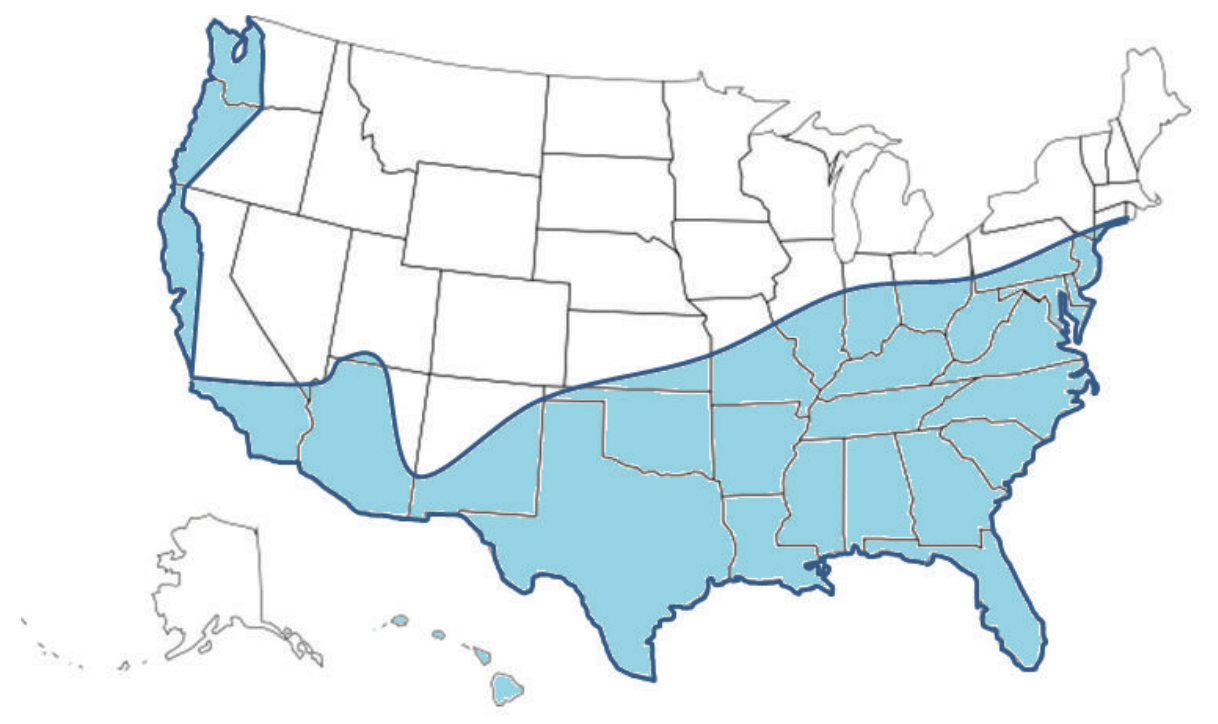

FIGURE 2: Map of the U.S. showing the areas at risk of dengue outbreaks, based on the approximate distribution of dengue mosquito vectors Aedes aegypti and Aedes albopictus. Map adapted from [28, 29]. The delimited area represents the approximate geographical area in which either dengue mosquito vector (Aedes aegypti and/or Aedes albopictus) have been found present in the USA and are therefore considered to be at risk for the establishment of dengue outbreaks. The noncontiguous states of Alaska and Hawaii are not shown at scale. U.S. territories are not shown.

the 2001-2002 epidemics, although most of the isolates analyzed belong to the "Pacific subtype" (genotype IV) of DENV-1, and cluster together with Tahitian DENV-1 strains, suggesting that Tahiti was the source of these strains. In contrast, the same study reported a single DENV-1 isolate from Hawaii obtained during 2001 from a traveler to Samoa that clustered outside the Tahitian cluster and that closely associated with a DENV-1 isolate previously obtained from another traveler to Samoa [39] (Figure 3).

\subsection{Dengue in American Samoa, Guam and Northern Mari-} ana Islands. Dengue was reported in American Samoa and Guam before 1950 [38] (Table 3). The main vector, Aedes aegypti, had been considered as eradicated from Guam since 1944. However, Aedes albopictus is abundantly present in the island [37]. Guam has not had dengue outbreaks in recent times, but it is at risk of dengue epidemics due to the presence of Aedes albopictus mosquitoes and the arrival of infected travelers from neighboring islands experiencing dengue activity.

Conversely, American Samoa had dengue epidemics in 1972 (DENV-2), 1975 (DENV-1), and 1995-1996 (DENV-3) $[38,40,71,72]$, while some dengue cases were reported in 1997 [41]. In 2001, more than 1,600 dengue suspected cases caused by DENV-1 were reported [42, 47], with 237 hospitalizations and three deaths due to DHF. In 2007, at least 63 dengue cases were confirmed, 23 of which were hospitalized [47]. Dengue activity was reported in 2008-2009; in 2009, an important outbreak of about 400 confirmed cases (for an incidence of 644/100,000 inhabitants) was registered [48].

In 2010, less than 100 dengue cases were reported for an incidence of 77/100,000 inhabitants [8, 48]. Epidemiological surveillance performed in 794 serum samples collected in three islands of American Samoa in 2010 revealed that 759 (95.6\%) of the tested individuals were positive for IgG antibodies to dengue [44]. The dengue vectors, Aedes aegypti and Aedes albopictus, are present in American Samoa [73].

There are reports indicating that individuals from the Northern Mariana Islands, without travel history, were seropositive for DENV (IgM and IgG) in 1998 in the island of Saipan [43], where DENV-2 was the DENV type implicated in those infections [42]. Furthermore, these islands suffered a dengue outbreak in 2001 with more than 1,400 cases reported [45]. Since then, no other dengue cases have been reported.

2.5. Dengue in US Virgin Islands. Dengue has been endemic in the USVI since at least 1924, when the first documented dengue epidemic in the Caribbean is thought to have started in the USVI [20]. These islands are located in close proximity to Puerto Rico, and include the four inhabited islands of St. Croix, St. Thomas, St. John and Water Island. Dengue outbreaks occurred in 1978 (DENV-1) and in 1990, this time involving DENV-1, DENV-2 and DENV-4; 1990 was the year of the first occurrence of DENV-4 in the USVI [20]. The sequence of a DENV-4 strain isolated in 1994 from St. Croix closely associated with strains that were circulating in Puerto Rico around the same time (Figure 4).

Forty dengue cases were reported in the island of St. Thomas in 2004. In 2005, a DENV-2 epidemic was reported in St. Croix, with 331 suspected cases of which $37 \%$ were laboratory-confirmed [65]. The sequence of a DENV-2 strain from the 2005 epidemic clustered within the clade IA of the American/Asian genotype, together with a number of strains from the Caribbean and South America [74].

During November 2012, 27 dengue cases were reported in the island of St. Croix, some of which were later laboratory 


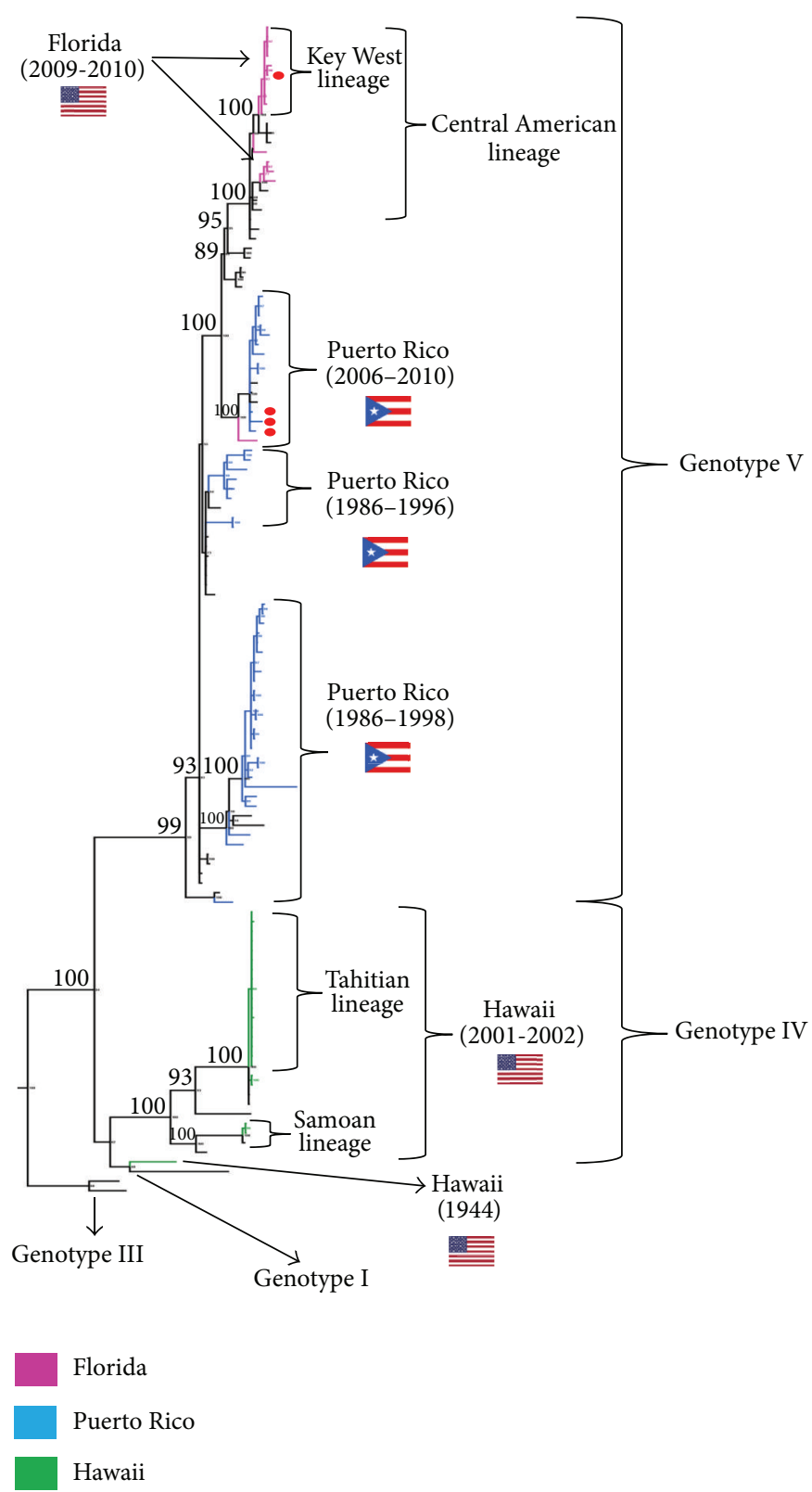

FIgURE 3: Phylogeny of DENV-1 in the USA and Puerto Rico. A consensus phylogenetic tree (50\% majority rule) was obtained by Bayesian phylogenetic analysis (Mr. Bayes, v. 3.2.) based on the envelope protein gene. Analysis included sequences of strains from Hawaii (2001-2002) $(n=21)$, Florida $(2009-2010)(n=15)$, and Puerto Rico $(1986-2010)(n=45)$ available in the GenBank database and representative sequences from DENV-1 genotypes I, III-V $(n=44)$. DENV-2, DENV-3, and DENV-4 were used to root the tree (not shown). Bayesian posterior probability values (>80) are shown for the principal nodes. Taxa are highlighted according to its geographical origin: Hawaii (green), Florida (pink), and Puerto Rico (light blue). A red dot identifies sequences obtained from blood donors.

confirmed. A serosurvey found that around $20 \%$ of the students and staff from a school in the island were positive for IgM antibodies to dengue; four students were positive for DENV-1 or DENV-4 RNA by PCR [69]. There is no available genetic information about the DENV strains circulating in St. Croix in 2012.

2.6. Dengue in Puerto Rico. Dengue is endemic in Puerto Rico, and cases have been reported every year for more than 50 years (Table 4 ). The public health definition of a dengue epidemic in Puerto Rico is based on a historical average: the event is called an epidemic when the number of cases detected by the passive surveillance system is higher than the 75th percentile of the distribution of cases for the same epidemiological week in previous years [75].

A large epidemic of DENV-3 involving approximately 27,000 individuals was reported in 1963-1964 [55, 56]. Another epidemic caused by DENV-2 occurred in 1969 [57]. Subsequently, sporadic dengue cases caused by DENV-2 were reported during the early 1970s [57]. In 1975, a case of 


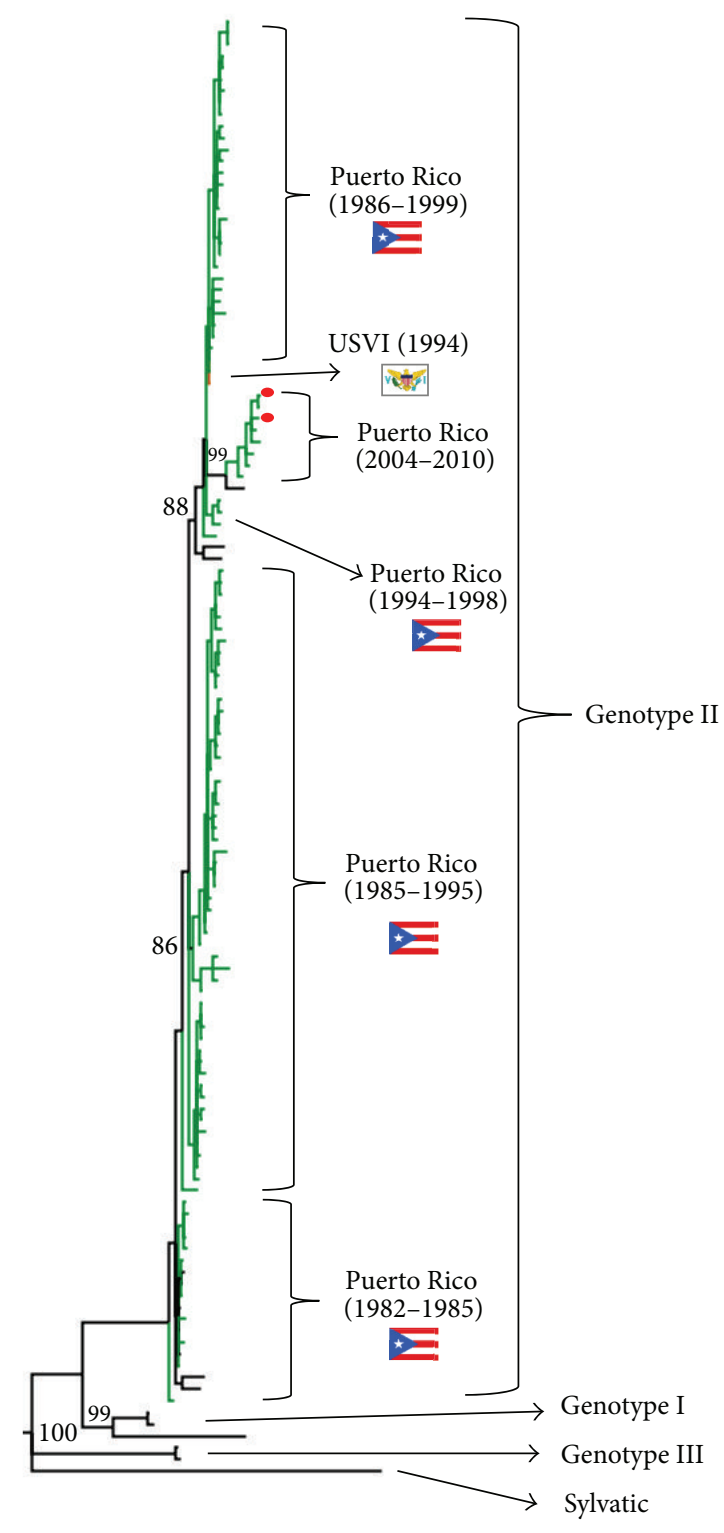

Puerto Rico

USVI

FIgURE 4: Phylogeny of DENV-4 in Puerto Rico and the US Virgin Islands (USVI). A consensus phylogenetic tree (50\% majority-rule) was obtained by Bayesian phylogenetic analysis (Mr. Bayes, v. 3.2.) based on the envelope protein gene. Analysis included sequences of strains from USVI (1994) $(n=1)$ and Puerto Rico (1982-2010) $(n=115)$ available in the GenBank database, and representative sequences from DENV-4 genotypes I-III and Sylvatic $(n=12)$. DENV-1, DENV-2, and DENV-3 were used to root the tree (not shown). Bayesian posterior probability values (>80) are shown for the principal nodes. Taxa are highlighted according to its geographical origin: Puerto Rico (green) and USVI (orange). A red dot identifies sequences obtained from blood donors.

DHF (associated with DENV-2) was reported for the first time in Puerto Rico and in the Western Hemisphere [20]. The outbreak in 1977 was caused by DENV-2, DENV-3 and DENV-1 (DENV types appear in order of frequency of detection), and that was the first documented occurrence of DENV-1 in the island [58].

The following year (1978), another dengue outbreak was reported, this time caused primarily by DENV-1 [59]. In 1981, an outbreak caused by DENV-4, and DENV-1 (in order of frequency) was reported and that was the first report of DENV-4 in the Americas [60]. Additional outbreaks followed in 1982 (DENV-4) [60, 61] and 1985-1986 (DENV-4, DENV1 and DENV-2, in order of frequency of detection), when a dengue epidemic caused 31 DHF cases and 3 deaths [62] (Table 4).

In 1994-1995, approximately 24,000 cases of dengue were reported in Puerto Rico, with circulation of DENV-2, DENV-4 and DENV-1 (in order of frequency of detection) 
Table 4: Dengue activity in Puerto Rico and the USA Virgin Islands, 1915-2013.

\begin{tabular}{|c|c|c|}
\hline Year(s) & Activity reported & References \\
\hline 1915 & Dengue epidemic reported in PR & {$[20]$} \\
\hline 1924 & 1st recorded epidemic of dengue in the Caribbean-Gulf-Atlantic region begun in the VI & {$[20]$} \\
\hline $1941-1946$ & Dengue epidemic reported in PR & {$[20]$} \\
\hline 1963 & Epidemic of $\approx 27,000$ cases $(D E N V-3)$ in $P R$ & {$[55,56]$} \\
\hline 1968-1969 & DENV-2 (only) epidemic, 1st report of DENV-2 in PR, 16,665 cases & [57] \\
\hline 1970-1974 & Sporadic DENV-2 cases reported in PR & {$[20,57]$} \\
\hline 1975 & $\begin{array}{l}\text { DHF suspected among } 3 \text { serologically confirmed dengue cases, shock seen in } 1 \text { patient in PR - DHF } \\
\text { described for the 1st time in the Western Hemisphere }\end{array}$ & {$[20,57]$} \\
\hline $1977-1978$ & $\begin{array}{l}\text { DENV-1 outbreak in } \mathrm{PR}, \approx 12,700 \text { cases, } 1 \text { st report of DENV-1 in PR, after DENV-2 and DENV-3 reports from } \\
\text { earlier during that year }\end{array}$ & {$[58,59]$} \\
\hline 1978 & DENV-1 outbreaks in VI & {$[20]$} \\
\hline $1981-1983$ & DENV-1 and DENV-4 outbreaks in PR, 1st reports of DENV-4 in both PR and the Americas & {$[60,61]$} \\
\hline 1985 & 2 DHF cases associated with DENV-4 in PR & {$[20,62]$} \\
\hline 1986 & Dengue epidemic in PR associated with DENV-4, 10,659 cases, 31 DHF cases, 3 deaths & {$[62]$} \\
\hline 1987 & 17 DHF cases in PR, 1 death & {$[20]$} \\
\hline 1988 & 8 DHF cases in PR & {$[20]$} \\
\hline \multirow{2}{*}{1989} & DENV-1, -2 , and -4 cases reported in PR, including 12 DHF cases, 5 deaths & {$[20]$} \\
\hline & Dengue cases reported in the VI & {$[20]$} \\
\hline \multirow{2}{*}{1990} & 6 DHF cases in PR, 1 death & {$[20]$} \\
\hline & Dengue cases reported, DENV-1, -2 , and -4 involved in outbreaks, 1 st report of DENV-4 in the VI & {$[20]$} \\
\hline 1991 & 14 DHF cases in PR, 1 death & {$[20]$} \\
\hline 1994 & $\approx 24,700$ cases of dengue reported in $\mathrm{PR}$ & {$[63]$} \\
\hline 1998 & $>17,000$ dengue cases reported in PR, 173 DHF cases, 9 deaths, all 4 serotypes isolated & {$[64]$} \\
\hline 1999 & All 4 serotypes reported present in PR, 34 DHF cases ( 6 deaths), 4,993 dengue cases & {$[20]$} \\
\hline 2000 & DENV-1, -2 and -3 , isolated in PR, 24 DHF cases, 2,433 dengue cases & {$[20]$} \\
\hline \multirow{2}{*}{2005} & Dengue reported in blood donors from PR, DENV-2 and DENV-3 isolated & {$[4]$} \\
\hline & Dengue epidemic reported in St. Croix, VI & {$[65]$} \\
\hline 2007 & $\begin{array}{l}\text { Epidemic caused by DENV-3, }-2,-1 \text {, and }-4 \text { (in order of frequency) in PR, more than 10,000 cases, } 227 \text { DHF } \\
\text { cases, } 40 \text { deaths. Dengue reported in blood donors from PR }\end{array}$ & {$[66]$} \\
\hline 2010 & $\begin{array}{l}\text { Largest epidemic in PR history, DENV-1, }-4,-2 \text {, and }-3 \text { isolated (in order of frequency), 26,766 cases reported, } \\
448 \text { DHF cases, } 128 \text { deaths. Dengue reported in blood donors from PR, DENV-1, DENV-4, and DENV-2 } \\
\text { isolated }\end{array}$ & {$[67]$} \\
\hline \multirow{2}{*}{2012} & Dengue epidemic in PR, 12,877 cases reported, DENV-1 and -4 isolated & {$[68]$} \\
\hline & Dengue epidemic in the VI & {$[69]$} \\
\hline $2013^{*}$ & Dengue epidemic in PR, $>5,000$ cases reported, DENV- 1 and -4 isolated & {$[70]$} \\
\hline
\end{tabular}

Adapted from [20]. PR: Puerto Rico, VI: USA Virgin Islands.

${ }^{*}$ As of May 20, 2013.

[63]. In 1998, over 17,000 dengue cases were reported, and for the first time the co-circulation of all four DENV types was observed. During this outbreak, DENV-3 was detected in the island after an absence of 20 years [64] (Table 4).

In 1999, all four DENV types co-circulated in the island resulting in 4,993 reported cases. The 2000 epidemic had cocirculation of DENV-1, DENV-2, and DENV-3 and resulted in 2,433 dengue cases reported [20]. DENV-3 was the predominant type in the inter-epidemic period between 1999 and 2003, to be later displaced by DENV-2 as the predominantly DENV type detected during the inter-epidemic period spanning from 2004 to 2006 [66].
In 2007 , a large epidemic (10,508 suspected dengue cases, with 227 fulfilling criteria for DHF) occurred after an interepidemic period of almost ten years; this epidemic was the second outbreak to have co-circulation of all DENV types, after the 1998 epidemic. During the 2007 dengue epidemic, 2,175 individuals tested positive for DENV RNA, of which $62 \%$ was infected with DENV-3, 31\% with DENV-2, 6\% with DENV-1, and $1 \%$ with DENV-4. DENV-1, and DENV-4 reappeared after approximately 9 years of absence (Table 4). Overall, an increased incidence of severe disease was reported in the 2007 epidemic when compared with previous outbreaks, resulting either from more efficient reporting of 
severe cases or from a true increase in the incidence of severe dengue [66].

The largest epidemic of dengue in Puerto Rico's history occurred during 2010, with almost 27,000 suspected dengue cases, of which more than 12,000 individuals (about $47 \%$ of tested cases) were laboratory-positive; more than 1,300 cases were classified as severe dengue, and there were 40 dengueassociated deaths (Table 4). The DENV types implicated in this epidemic were in order of frequency DENV-1 (69\%), DENV-4 (23.7\%), and DENV-2 (7.3\%), with only two DENV3 cases reported $(<0.1 \%)$. The 2010 epidemic is considered the longest-lasting dengue outbreak ever registered in Puerto Rico, with cases starting to appear during the first week of 2010, peaking around August and returning to levels below the historical average in December of that year [67].

In 2012, an epidemic resulted in 12,877 suspected cases reported, of which 5,652 (44\%) were laboratory confirmed. DENV-1 and DENV-4 were the predominant types detected, similar to the 2010 epidemic [68], (Figure 1). This outbreak has continued into 2013, although with a declining trend. Up to April 22, 2013, 5,251 dengue suspected cases had been reported, 2,573 (49\%) of which were laboratory-confirmed, and similar to the observed during the 2012 epidemic, DENV$1(78 \%)$ and DENV-4 (21\%) were the DENV types predominantly reported [70], (Figure 1).

2.6.1. Epidemiological Data Obtained from Asymptomatic Infections in Blood Donors. Because DENV can be transmitted by blood transfusion $[4,6]$ and infection can be asymptomatic [1-3], there is great concern about DENV activity among blood donors in endemic places in the absence of overt epidemic and during epidemic times. Prevalence studies in blood donors have been performed in various areas around the world where DENV is endemic [76].

A study performed in asymptomatic blood donors from Puerto Rico during the inter-epidemic year 2005 reported that $0.7 \%$ (12 out of 16,521) blood donations tested positive for DENV RNA. Of these, three donors were identified by TaqMan as infected with DENV-2 and one with DENV-3, which were the DENV types circulating in the island during that year (Figure 1). Two of the DENV-2 and the DENV-3 strains were isolated in cell culture or by mosquito inoculation [4]. Another study conducted among blood donors during the epidemic year of 2007 found that 29 out of 15,350 donations tested positive for DENV RNA using an assay that detects all four DENV types but does not discriminate between DENV types. Discriminatory real-time PCR detected 12 positive samples: one was identified as DENV-1, four as DENV-2, and seven as DENV-3 (Figure 1). All these 12 samples were infectious in C6/36 cell cultures [6].

Study of DENV strains circulating in 2010 performed in blood donors [50] and in symptomatic cases [67] showed that these DENV-1 strains belong to the genotype $\mathrm{V}$ (the only one found to circulate in the Americas to date) but were from a lineage different from those that circulated in Puerto Rico during and before 1998 (Figure 3). Likewise, the sequenced DENV-4 strains from 2010 were found to belong to the genotype II (also the only one circulating in the Americas) and are distinct from those that circulated in Puerto Rico in the 1990s, although with less genetic variation than that observed in the newest DENV-1 strains circulating in the island (Figure 4). The results suggest that overall, a clade replacement for DENV-1 and DENV-4 may have occurred at some point in Puerto Rico during the inter-epidemic period between 1999 and $2006[50,67]$.

\section{Conclusions}

Dengue has emerged and re-emerged in many locations around the world, including countries in Europe (e.g., France and Croatia) [77, 78] and in North America [24] during the last two decades. Dengue has reemerged and caused epidemics in the continental USA for the first time after several decades of absence, and a worrisome panorama is expected if the trend of transmission continues. Several articles expressing these concerns have been published before and after the re-emergence of dengue in Florida in 2009 [79, 80]. Such concern is augmented by evolving climatic and ecological conditions that favor vector sustainability and by high travel activity with subsequent importation of cases. In fact, cases of dengue in returning travelers to the USA have been on the rise [81], and cases of dengue in countries in Central America, South America, and the Caribbean, very popular destinations for American tourists, have also been on the rise in the past decades [82].

Although the primary mosquito vector for dengue is Aedes aegypti, a highly domesticated urban mosquito, the virus can be also transmitted by Aedes albopictus, albeit in a less efficient manner. Aedes albopictus is probably responsible for the maintenance of dengue in rural/sylvatic cycles in endemic countries [83], and future research should address the biological and epidemiological implications of the displacement and replacement of Aedes species in the context of dengue epidemics.

In the case of the USA, both dengue vector species are widely distributed in the southern parts of the country (Figure 2), and one or another dengue vector is present in all US insular territories [28, 29]. Travel, especially by air, has been considered an important risk factor for the rapid dissemination of pathogens and their vectors in an efficient and rapid manner [84-87]. New promising vector control strategies based on the release of Wolbachia-infected Aedes aegypti mosquitoes have been tested in regions of Australia with potential for the occurrence of dengue epidemics and if deemed suitable, this approach could be utilized in endemic regions from Asia and the Americas [88].

Many large cities in the US are important hubs for air travel and therefore receive a high number of individuals potentially infected with pathogens that cause asymptomatic disease, including several arboviruses (e.g., dengue viruses, Japanese Encephalitis virus and Chikungunya virus). Thus, there is an increasing risk of introduction of these "exotic" pathogens to urban conglomerates where mosquito vectors are present or have the potential to become established (e.g., Miami, Atlanta, Baltimore/Washington, D.C., and New York City in the East Coast, and Los Angeles and San Francisco in the West Coast). 
Despite the current economic and budgetary constraints, strict mosquito control policies and activities, that may include both traditional and biological vector control strategies, must be implemented and maintained in localities that have the potential to become the port of entry for these viruses and become the focus for another dengue epidemic in the USA.

\section{Acknowledgment}

The authors want to thank Dr. Celso Bianco for his critical reading, comments, and suggestions on the paper.

\section{References}

[1] D. J. Gubler, "Dengue and dengue hemorrhagic fever," Clinical Microbiology Reviews, vol. 11, no. 3, pp. 480-496, 1998.

[2] World Health Organization, Dengue Haemorrhagic Fever: Diagnosis, Treatment, Prevention and Control, World Health Organization, Geneva, Switzerland, 2nd edition, 1997.

[3] World Health Organization, Dengue: Guidelines for Diagnosis, Treatment, Prevention and Control, World Health Organization, Geneva, Switzerland, New edition, 2009.

[4] H. Mohammed, J. M. Linnen, J. L. Muhoz-Jorddn et al., "Dengue virus in blood donations, Puerto Rico, 2005," Transfusion, vol. 48, no. 7, pp. 1348-1354, 2008.

[5] K. Tangnararatchakit, W. Tirapanich, W. Tapaneya-Olarn et al., "Severe nonfebrile dengue infection in an adolescent after postoperative kidney transplantation: a case report," Transplantation Proceedings, vol. 44, no. 1, pp. 303-306, 2012.

[6] S. L. Stramer, J. M. Linnen, J. M. Carrick et al., "Dengue viremia in blood donors identified by RNA and detection of dengue transfusion transmission during the 2007 dengue outbreak in Puerto Rico," Transfusion, vol. 52, no. 8, pp. 1657-1666, 2012.

[7] R. Chen and N. Vasilakis, "Dengue-quo tu et quo vadis?" Viruses, vol. 3, no. 9, pp. 1562-1608, 2011.

[8] O. J. Brady, P. W. Gething, S. Bhatt et al., "Refining the global spatial limits of dengue virus transmission by evidence-based consensus," PLoS Neglected Tropical Diseases, vol. 6, no. 8, Article ID e1760, 2012.

[9] M. G. Guzman, M. Alvarez, and S. B. Halstead, "Secondary infection as a risk factor for dengue hemorrhagic fever/dengue shock syndrome: an historical perspective and role of antibodydependent enhancement of infection," Archives of Virology, 2013.

[10] S. Bhatt, P. W. Gething, O. J. Brady et al., "The global distribution and burden of dengue," Nature, vol. 496, no. 7446, pp. 504-507, 2013.

[11] D. J. Gubler, "Epidemic dengue/dengue hemorrhagic fever as a public health, social and economic problem in the 21st century," Trends in Microbiology, vol. 10, no. 2, pp. 100-103, 2002.

[12] G. Añez, R. Balza, N. Valero, and Y. Larreal, "Economic impact of dengue and dengue hemorrhagic fever in the State of Zulia, Venezuela, 1997-2003," Revista Panamericana de Salud Publica, vol. 19, no. 5, pp. 314-320, 2006.

[13] M. G. Guzman, S. B. Halstead, H. Artsob et al., "Dengue: a continuing global threat," Nature Reviews Microbiology, vol. 8, supplement 12, pp. S7-S16, 2010.

[14] S. S. Whitehead, J. E. Blaney, A. P. Durbin, and B. R. Murphy, "Prospects for a dengue virus vaccine," Nature Reviews Microbiology, vol. 5, no. 7, pp. 518-528, 2007.
[15] J. M. Medlock, K. M. Hansford, F. Schaffner et al., "A review of the invasive mosquitoes in Europe: ecology, public health risks, and control options," Vector-Borne and Zoonotic Diseases, vol. 12, no. 6, pp. 435-447, 2012.

[16] J. E. Brown, V. Obas, V. Morley, and J. R. Powell, "Phylogeography and spatio-temporal genetic variation of Aedes aegypti (Diptera: Culicidae) populations in the Florida Keys," Journal of Medical Entomology, vol. 50, no. 2, pp. 294-299, 2013.

[17] F. Schaffner, J. M. Medlock, and W. Van Bortel, "Public health significance of invasive mosquitoes in Europe," Clinical Microbiology and Infection, 2013.

[18] H. P. Mohammed, M. M. Ramos, A. Rivera et al., "Travel-associated dengue infections in the United States, 1996 to 2005," Journal of Travel Medicine, vol. 17, no. 1, pp. 8-14, 2010.

[19] A. B. Rush, "An account of the bilious remitting fever, as it appeared in Philadelphia in the summer and autumn of the year 1780," in Medical Enquiries and Observations, pp. 104-117, Prichard and Hall, Philadelphia, Pa, USA, 1789.

[20] J. Schneider and D. Droll, "A timeline for dengue in the Americas to December 31, 2000 and noted first occurrences," 2001, http://www.paho.org/English/HCP/HCT/dengue_timeline.xls .

[21] U. S. Centers for Disease Control and Prevention, "DengueTexas," Morbility and Mortality Weekly Reports, vol. 29, article 451, 1980.

[22] U. S. Centers for Disease Control and Prevention, "Imported and indigenous dengue fever-United States, 1986," Morbility and Mortality Weekly Reports, vol. 36, pp. 551-554, 1987.

[23] M. D. Malison and S. H. Waterman, "Dengue fever in the United States. A report of a cluster of imported cases and review of the clinical, epidemiologic, and public health aspects of the disease," Journal of the American Medical Association, vol. 249, no. 4, pp. 496-500, 1983.

[24] U. S. Centers for Disease Control and Prevention, "Locally acquired dengue-Key West, Florida, 2009-2010," Morbility and Mortality Weekly Reports, vol. 59, no. 19, pp. 577-581, 2010.

[25] Florida State Department of Health, http://www.doh.state.fl.us/ Environment/medicine/arboviral/Weekly-Summary.html.

[26] Florida State Department of Health, http://www.doh.state.fl.us/ Environment/medicine/arboviral/weeklyreportarchive.html.

[27] U. S. Department of State, 2013, Executive Order 13423 Sec. 9. (1), http://www.state.gov/documents/organization/155653.pdf .

[28] K. Knowlton, G. Solomon, and M. Rotkin-Ellman, "MosquitoBorne dengue fever threat spreading in the Americas," NRDC Issue Paper, Natural Resources Defense Council, New York, NY, USA, 2009, http://www.nrdc.org/health/dengue/files/ dengue.pdf.

[29] M. Q. Benedict, R. S. Levine, W. A. Hawley, and L. P. Lounibos, "Spread of the tiger: global risk of invasion by the mosquito Aedes albopictus," Vector-Borne and Zoonotic Diseases, vol. 7, no. 1, pp. 76-85, 2007.

[30] B. Hafkin, J. E. Kaplan, C. Reed et al., "Reintroduction of dengue fever into the continental United States. I. Dengue surveillance in Texas, 1980," The American Journal of Tropical Medicine and Hygiene, vol. 31, no. 6, pp. 1222-1228, 1982.

[31] U.S. Centers for Disease Control and Prevention, "Dengue fever at the U.S. Mexico border, 1995-1996," Morbility and Mortality Weekly Reports, vol. 45, no. 39, pp. 841-844, 1996.

[32] U. S. Centers for Disease Control and Prevention, "Dengue hemorrhagic fever-U.S. Mexico border, 2005," Morbility and Mortality Weekly Reports, vol. 56, pp. 785-789, 2007. 
[33] P. Reiter, S. Lathrop, M. Bunning et al., “Texas lifestyle limits transmission of dengue virus," Emerging Infectious Diseases, vol. 9, no. 1, pp. 86-89, 2003.

[34] D. J. Gubler, "Dengue and dengue hemorrhagic fever: its history and resurgence as a global public health problem," in Dengue and Dengue Hemorrhagic Fever, D. J. Gubler and G. Kuno, Eds., pp. 1-22, CAB International, New York, NY, USA, 1997.

[35] G. W. Wilson, "Epidemic of dengue in the territory of Hawaii during 1903," Public Health Reports, vol. 19, pp. 67-70, 1904.

[36] A. B. Sabin, "Research on dengue during World War II," The American journal of tropical medicine and hygiene, vol. 1, no. 1, pp. 30-50, 1952.

[37] L. Guillaumot, R. Ofanoa, L. Swillen et al., "Distribution of Aedes albopictus (Diptera, Culicidae) in southwestern Pacific countries, with a first report from the Kingdom of Tonga," Parasites \& Vectors, vol. 5, p. 247, 2012.

[38] T. Kiedrzynski, Y. Souares, and T. Stewart, "Dengue in the Pacific: an updated history," Pacific Health Dialog, vol. 5, no. 1, pp. 129-136, 1998.

[39] A. Imrie, Z. Zhao, S. N. Bennett, P. Kitsutani, M. Laille, and P. Effler, "Molecular epidemiology of dengue in the Pacific: introduction of two distinct strains of the dengue 2 type- 1 virus into Hawaii," Annals of Tropical Medicine and Parasitology, vol. 100, no. 4, pp. 327-336, 2006.

[40] N. G. Gratz and A. B. Knudsen, The Rise and Spread of Dengue, Dengue Haemorrhagic Fever and Its Vectors. An Historical Review (Up to 1995), CTD/FIL(DEN) 96. 7, WHO, Geneva, Switzerland.

[41] PROMED, "PRO>Dengue-American Samoa," 19970829. 1827., 1997.

[42] N. Singh, T. Kiedrzynski, C. Lepers, and E. K. Benyon, "Dengue in the Pacific - an update of the current situation," Pacific Health Surveillance and Response, vol. 12, no. 2, pp. 111-119, 2005.

[43] T. Kiedrzynski, "PRO/EDR>dengue-Saipan (04)," 19980607. 1089, 1998.

[44] J. Duncombe, C. Lau, P. Weinstein et al., "Seroprevalence of dengue in American Samoa, 2010," Emerging Infectious Diseases, vol. 19, no. 2, pp. 324-326, 2013.

[45] GIDEON, (2011) Global Infectious Diseases and Epidemiology Online Network (GIDEON) database [Graph 14483. 01] Northern Marianas. Dengue, cases Notes: 1. 2001-No fatal cases reported.

[46] T. Jelinek, G. Dobler, and H. D. Nothdurft, "Evidence of dengue virus infection in a German couple returning from Hawaii," Journal of Travel Medicine, vol. 5, no. 1, pp. 44-45, 1998.

[47] PROMED, “DENGUE/DHF UPDATE, 2007 (30)," ProMED, 2007.

[48] Y. Arima and T. Matsui, "Epidemiologic update on the dengue situation in the Western Pacific Region, 2010," Western Pacific Surveillance and Response Journal, vol. 2, no. 2, pp. 4-8, 2011.

[49] A. S. Graham, C. A. Pruszynski, L. J. Hribar et al., "Mosquitoassociated dengue virus, Key West, Florida, USA, 2010," Emerging Infectious Diseases, vol. 17, no. 11, pp. 2074-2075, 2011.

[50] G. Añez, D. A. Heisey, L. M. Espina et al., "Phylogenetic analysis of dengue virus types 1 and 4 circulating in Puerto Rico and Key West, Florida, during 2010 epidemics," The American Journal of Tropical Medicine and Hygiene, vol. 87, no. 3, pp. 548-553, 2012.

[51] J. L. Muñoz-Jordan, G. A. Santiago, H. Margolis, and L. Stark, "Genetic relatedness of dengue viruses in Key West, Florida, USA, 2009-2010," Emerging Infectious Diseases, vol. 19, no. 4, pp. 652-654, 2013.
[52] R. I. Usinger, "Entomological phases of the recent dengue epidemic in Honolulu," Public Health Reports, vol. 59, pp. 423-430, 1944.

[53] W. E. Gilbertson, "Sanitary aspects of the control of the 194344 epidemic of dengue fever in Honolulu," American Journal of Public Health, vol. 35, no. 3, pp. 261-270, 1945.

[54] P. V. Effler, L. Pang, P. Kitsutani et al., "Dengue fever, Hawaii, 2001-2002," Emerging Infectious Diseases, vol. 11, no. 5, pp. 742749, 2005.

[55] J. M. Neff, L. Morris, R. Gonzalez-alcover, P. H. Coleman, S. B. Lyss, and H. Negron, "Dengue fever in a puerto rican community," American Journal of Epidemiology, vol. 86, no. 1, pp. 162184, 1967.

[56] P. K. Russell, E. L. Buescher, J. M. McCown, and J. Ordõnez, "Recovery of dengue viruses from patients during epidemics in Puerto Rico and East Pakistan," The American Journal of Tropical Medicine and Hygiene, vol. 15, no. 4, pp. 573-579, 1966.

[57] W. H. Likosky, C. H. Calisher, and A. L. Michelson, "An epidemiologic study of dengue type 2 in Puerto Rico, 1969," American Journal of Epidemiology, vol. 97, no. 4, pp. 264-275, 1973.

[58] D. M. Morens, J. G. Rigau-Perez, and R. H. Lopez-Correa, "Dengue in Puerto Rico, 1977: public health response to characterize and control an epidemic of multiple serotypes," The American Journal of Tropical Medicine and Hygiene, vol. 35, no. 1, pp. 197-211, 1986.

[59] D. J. Gubler, "Dengue and dengue hemorrhagic in the Americas," in Dengue Hemorrhagic Fever, P. Thongcharoen, Ed., pp. 9-22, World Health Organization, Geneva, Switzerland, 1993.

[60] D. J. Gubler, G. Kuno, and G. E. Sather, "Mosquito cell cultures and specific monoclonal antibodies in surveillance for dengue viruses," The American Journal of Tropical Medicine and Hygiene, vol. 33, no. 1, pp. 158-165, 1984.

[61] S. H. Waterman, R. J. Novak, and G. E. Sather, "Dengue transmission in two Puerto Rican communities in 1982," The American Journal of Tropical Medicine and Hygiene, vol. 34, no. 3, pp. 625-632, 1985.

[62] V. Dietz, D. J. Gubler, S. Ortiz et al., "The 1986 dengue and dengue hemorrhagic fever epidemic in Puerto Rico: epidemiologic and clinical observations," Puerto Rico health sciences journal, vol. 15, no. 3, pp. 201-210, 1996.

[63] J. G. Rigau-Pérez, A. V. Vorndam, and G. G. Clark, “The dengue and dengue hemorrhagic fever epidemic in Puerto Rico, 19941995," The American Journal of Tropical Medicine and Hygiene, vol. 64, no. 1-2, pp. 67-74, 2001.

[64] J. G. Rigau-Pérez, A. Ayala-López, E. J. García-Rivera et al., “The reappearance of dengue- 3 and a subsequent dengue- 4 and dengue-1 epidemic in Puerto Rico in 1998," The American Journal of Tropical Medicine and Hygiene, vol. 67, no. 4, pp. 355-362, 2002.

[65] H. Mohammed, M. Ramos, J. Armstrong et al., "An outbreak of dengue fever in St. Croix (US Virgin Islands), 2005," PLoS ONE, vol. 5, no. 10, Article ID e13729, 2010.

[66] K. M. Tomashek, A. Rivera, J. L. Muñoz-Jordan et al., "Description of a large island-wide outbreak of dengue in Puerto Rico, 2007," The American Journal of Tropical Medicine and Hygiene, vol. 81, no. 3, pp. 467-474, 2009.

[67] T. M. Sharp, E. Hunsperger, G. A. Santiago et al., "Virus-specific differences in rates of disease during the 2010 dengue epidemic in Puerto Rico," PLoS Neglected Tropical Diseases, vol. 7, no. 4, Article ID e2159, 2013. 
[68] Departamento de Salud de Puerto Rico, http://www.salud.gov .pr/Datos/VDengue/InfSemanales/Informe\%20Semanal\% (202012/Informe\%20Semana\%20Semana\%2052).pdf.

[69] U. S. Centers for Disease Control and Prevention, "Notes from the field: school reporting of a dengue outbreak-St. Croix, U.S. Virgin Islands," Morbility and Mortality Weekly Reports, vol. 62, no. 9, p. 172, 2012.

[70] Departamento de Salud de Puerto Rico, http://www.salud.gov .pr/Datos/Dengue/Informes\%20CDC\%202013/Informe\%20 Dengue\%20Semana\%2013.pdf.

[71] PROMED, “PROMED-EDR: dengue-Samoa (2)," 19960208. 0268, 1996.

[72] D. Gubler, T. Kuberski, and L. Rosen, "Dengue in American Samoa," in Proceedings of the 2nd International Congress of the Pacific Science Association, Working Paper, Agana, Guam, USA, May 1973.

[73] T. R. Burkot, T. Handzel, M. A. Schmaedick, J. Tufa, J. M. Roberts, and P. M. Graves, "Productivity of natural and artificial containers for Aedes polynesiensis and Aedes aegypti in four American Samoan villages," Medical and Veterinary Entomology, vol. 21, no. 1, pp. 22-29, 2007.

[74] K. L. McElroy, G. A. Santiago, N. J. Lennon, B. W. Birren, M. R. Henn, and J. L. Muñoz-Jordán, "Endurance, refuge, and reemergence of dengue virus type 2, Puerto Rico, 1986-2007," Emerging Infectious Diseases, vol. 17, no. 1, pp. 64-71, 2011.

[75] U. S. Centers for Disease Control and Prevention, http://www .cdc.gov/dengue/resources/wklyrpt_eng/wklyrpt_eng.pdf.

[76] J. M. Linnen, E. Vinelli, E. C. Sabino et al., "Dengue viremia in blood donors from Honduras, Brazil, and Australia," Transfusion, vol. 48, no. 7, pp. 1355-1362, 2008.

[77] I. C. Kurolt, L. Betica-Radić, O. Daković-Rode et al., "Molecular characterization of dengue virus 1 from autochthonous dengue fever cases in Croatia," Clinical Microbiology and Infection, vol. 19, no. 3, pp. E163-E165, 2013.

[78] G. La Ruche, Y. Souarès, A. Armengaud et al., "First two autochthonous dengue virus infections in metropolitan France, September 2010," Euro Surveillance, vol. 15, no. 39, p. 19676, 2010.

[79] D. M. Morens and A. S. Fauci, "Dengue and hemorrhagic fever: a potential threat to public health in the United States," Journal of the American Medical Association, vol. 299, no. 2, pp. 214-216, 2008.

[80] A. A. Adalja, T. K. Sell, N. Bouri, and C. Franco, "Lessons learned during dengue outbreaks in the United States, 20012011," Emerging Infectious Diseases, vol. 18, no. 4, pp. 608-614, 2012.

[81] A. Wilder-Smith and E. Schwartz, "Dengue in travelers," The New England Journal of Medicine, vol. 353, no. 9, pp. 924-932, 2005.

[82] J. L. San Martín, O. Brathwaite, B. Zambrano et al., "The epidemiology of dengue in the Americas over the last three decades: a worrisome reality," The American Journal of Tropical Medicine and Hygiene, vol. 82, no. 1, pp. 12-35, 2010.

[83] N. G. Gratz, "Critical review of the vector status of Aedes albopictus," Medical and Veterinary Entomology, vol. 18, no. 3, pp. 215-227, 2004.

[84] K. T. Goh, S. K. Ng, and S. Kumarapathy, "Disease-bearing insects brought in by international aircraft into Singapore," Southeast Asian Journal of Tropical Medicine and Public Health, vol. 16, no. 1, pp. 49-53, 1985.

[85] M. W. Service, "Mosquito (Diptera: Culicidae) dispersal-the long and short of it," Journal of Medical Entomology, vol. 34, no. 6, pp. 579-588, 1997.
[86] R. Eritja, H. D. Ramos, and C. Aranda, "Aircraft-mediated mosquito transport: new direct evidence," Journal of the American Mosquito Control Association, vol. 16, no. 4, p. 339, 2000.

[87] A. J. Tatem, S. I. Hay, and D. J. Rogers, "Global traffic and disease vector dispersal," Proceedings of the National Academy of Sciences of the United States of America, vol. 103, no. 16, pp. 6242$6247,2006$.

[88] I. Iturbe-Ormaetxe, T. Walker, and S. L. O’Neill, "Wolbachia and the biological control of mosquito-borne disease," EMBO Reports, vol. 12, no. 6, pp. 508-518, 2011. 

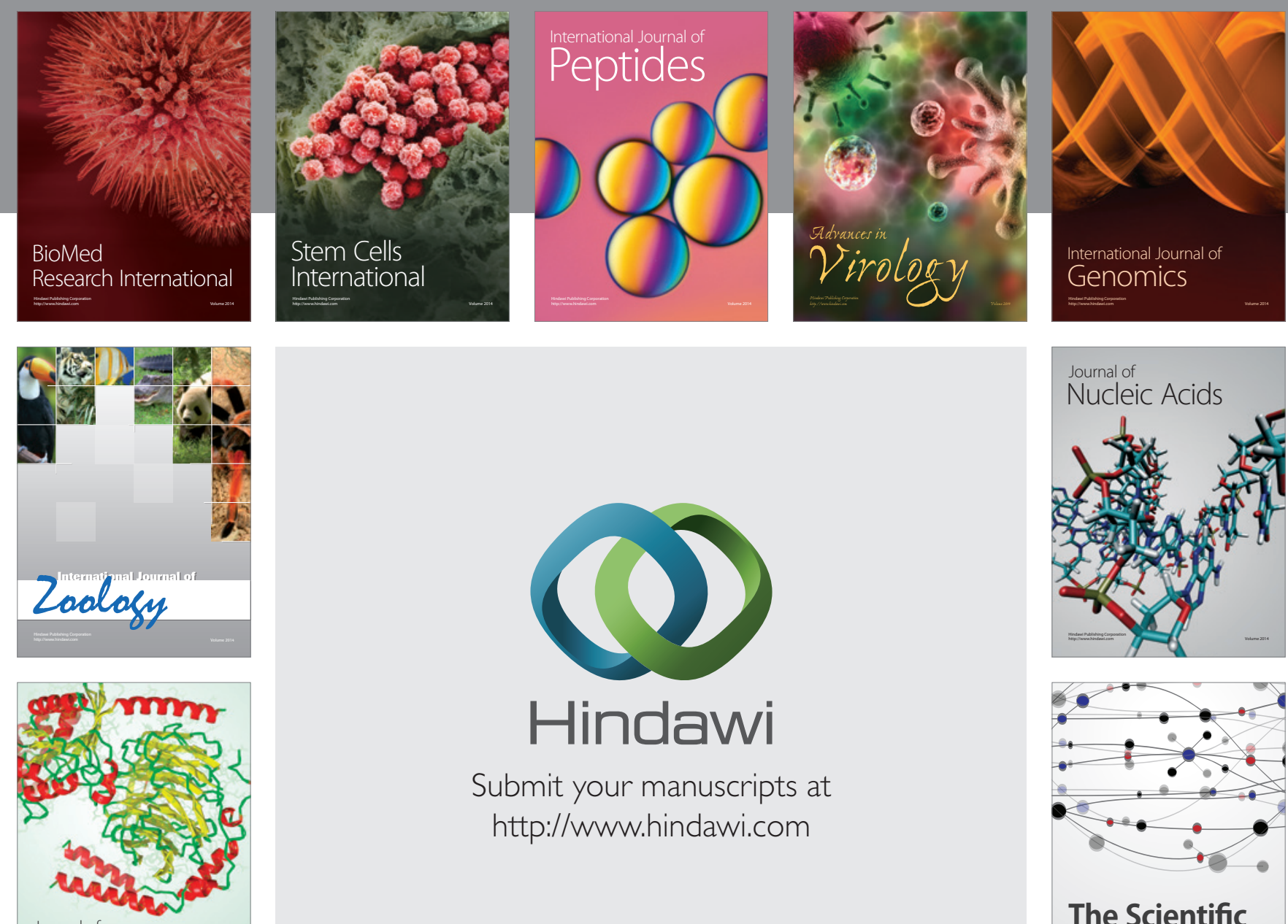

Submit your manuscripts at

http://www.hindawi.com

Journal of
Signal Transduction
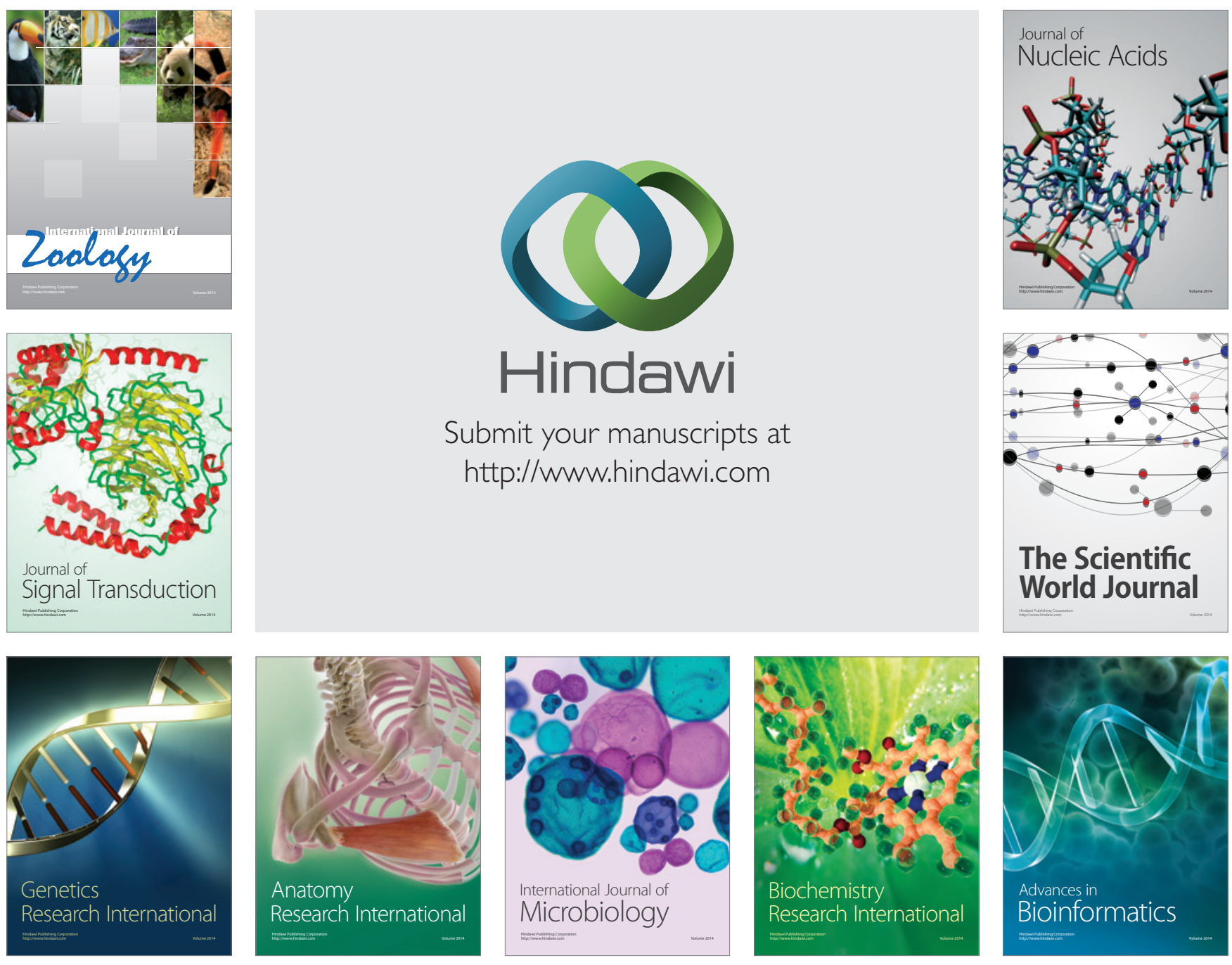

The Scientific World Journal
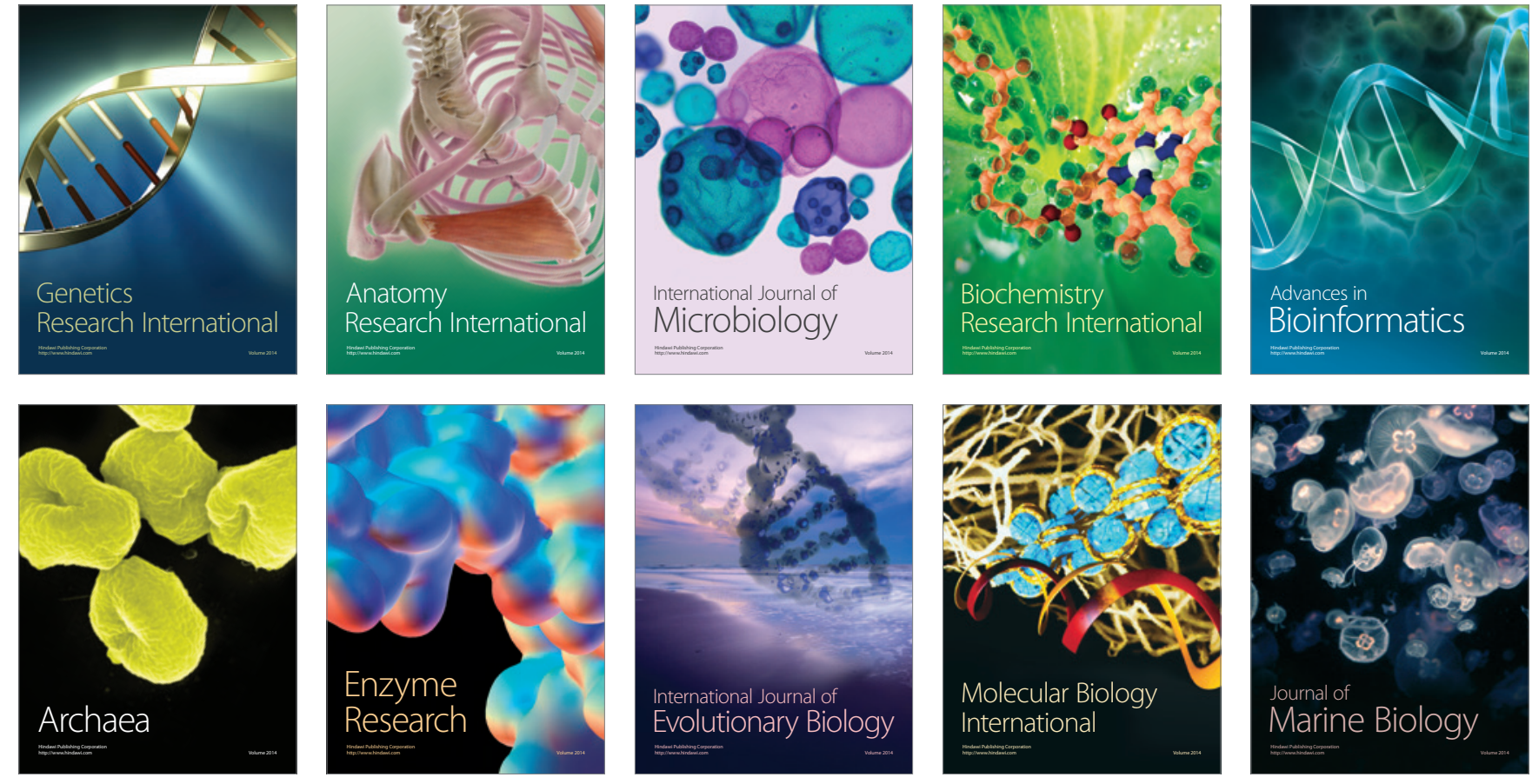